\title{
Vincristine Sulfate Liposome
}

National Cancer Institute

\section{Source}

National Cancer Institute. Vincristine Sulfate Liposome. NCI Thesaurus. Code C2702.

A sphing omyelin/cholesterol liposomal formulation of vincristine sulfate with potential antineoplastic activity. Vincristine, a vinca alkaloid isolated from the plant Vinca rosea, irreversibly binds to and stabilizes tubulin, thereby interrupting microtubule assembly/disassembly dynamics, thereby preventing the formation of the mitotic spindle and leading to cell cycle arrest in metaphase. Liposomal encapsulation prolongs bioavailability of vincristine, increases its delivery to tumor tissues and reduces its toxicity profile. Compared to standard liposomal delivery, sphing osomal drug delivery further increases circulation time of serum drug and enhances drug accumulation at tumor sites, thereby leading to a further increase in efficacy. 